\title{
Stock Identification of Gag, Mycteroperca microlepis, Along the Southeast Coast of the United States
}

\author{
Robert W. Chapman, ${ }^{1 \star}$ George R. Sedberry, ${ }^{1}$ Christopher C. Koenig, ${ }^{2}$ and Brandon M. Eleby ${ }^{1}$ \\ ${ }^{1}$ Marine Resources Research Institute, SCDNR, P.O. Box 12559, Charleston, SC 29422-2559, U.S.A. \\ ${ }^{2}$ Department of Biological Sciences, Florida State University, Tallahassee, FL 32306-2043, U.S.A.
}

\begin{abstract}
The gag grouper Mycteroperca microlepis is an important component of commercial and recreational fisheries along the South Atlantic coast of the United States and in the Gulf of Mexico. Over the past two decades, this species has experienced significant declines in abundance and an increasing skew in sex ratios. Analysis of microsatellite DNA variation in this species shows mosaic patterns of population subdivision and significant departures from Hardy-Weinberg equilibrium in all sampling locations. Given the length of the pelagic stage (egg and larvae), the prevailing current patterns, and the migratory capabilities of the adults, it is unlikely that these observations are the result of restricted gene flow among genetically differentiated populations. The apparent structure of gag populations most likely reflects inbreeding in size-limited populations. Population declines, skewed sex ratios, and perhaps variance in female fecundity appear to have acted in concert to limited the number of individuals that contribute to a given year class. These data are reinforced by studies of other fish stocks that have experienced precipitous declines over the past two decades.
\end{abstract}

Key words: gag grouper, Mycteroperca microlepis, population decline, inbreeding, sex ratio, stock identification

\section{INTRODUCTION}

Many species of epinepheline fishes, commonly called groupers, undertake annual migrations to well-defined locations to spawn (Colin et al., 1987; Shapiro, 1987; Carter, 1989; Waschkewitz and Wirtz, 1990; Sadovy et al., 1994). In some cases these migrations are believed to be to natal waters, which are thought to possess favorable hydrographic conditions that enhance survival of larvae (Richards and Lindeman, 1987; Waschkewitz and Wirtz, 1990). Grouper spawning aggregations are often heavily fished (Craig, 1969; Carter, 1989), and this may reduce population abundance throughout the range if most individuals are spawning in a few locations. Fishing of spawning aggregations can have serious deleterious effects on the population size, genetic diversity, and behavior of species that aggregate (Craig, 1969; Nelson and Soule, 1987; Carter, 1989), and special management for spawning areas should be considered.

Gag, Mycteroperca microlepis, is the most frequently landed grouper in commercial and recreational reef fish fisheries in South Carolina. Although many aspects of gag life history have been described (e.g., Collins et al., 1987; Keener et al., 1988; McGovern et al., 1998), information from the Atlantic Coast of the southeastern United States on spawning location, recruitment sources, and stock identification is limited or lacking. Tagging data suggest that some gag off South Carolina may migrate to southern 
Florida (Van Sant et al., 1994; MARMAP unpublished results). Although very limited, these data are supported by observations from commercial fishermen and sport divers in southern Florida (Ben Hartig and Bill Parks, personal communications), who describe a historical pattern of migration of gag to the narrow east Florida shelf near West Palm Beach, in winter. If such a spawning migration does occur, the ramifications for management of gag would be significant. Careful management of the species requires that life history be well understood, and that the species be afforded protective management such that reproduction is ensured.

Over the past two decades, gag populations have declined by as much as an order of magnitude in some areas (McGovern et al., 1998), female-to-male sex ratios have changed from about 8:1 to about 30:1 (Coleman et al., 1996; Koenig et al., 1996), and age of sexual maturity has declined substantially. Declines in abundance, changing sex ratios, and evidence of a spawning migration suggest that a proposed spawning season closure might be necessary, but only in the waters off Florida. The spawning migration suggested by limited tagging data (Van Sant et al., 1994) would result in a single genetic stock of gag if all fish from the region migrate to narrowly defined spawning areas off Florida.

The objective of this study was to use microsatellite variation to identify stocks of gag along the southeast Atlantic Coast and in the Gulf of Mexico. We hypothesized that a single population of gag occurs in the Atlantic between Cape Fear and South Florida (south of Cape Canaveral), with a separate stock in the northeastern Gulf of Mexico. Another component of this study was motivated by the population declines, skewed sex ratios, early onset of sexual maturity, and sex reversal. Collectively these features could impact the distribution of genetic variation in the species owing to their effects on effective population sizes $\left(N_{e}\right)$.

One difficulty in interpreting the results of multilocus data is that some loci may indicate that populations are genetically distinct and other loci will indicate genetic homogeneity. Likewise, some loci may indicate that a population does not conform to the expectations of HardyWeinberg (HW) equilibrium, while others do not show significant deviations. The question becomes, which loci do we believe? Are the populations genetically distinct? Are the samples taken from Mendelian populations? We have developed a procedure using a maximum likelihood approach to examine these problems. The procedure allows one to examine the likelihood that some portion of the loci will, by

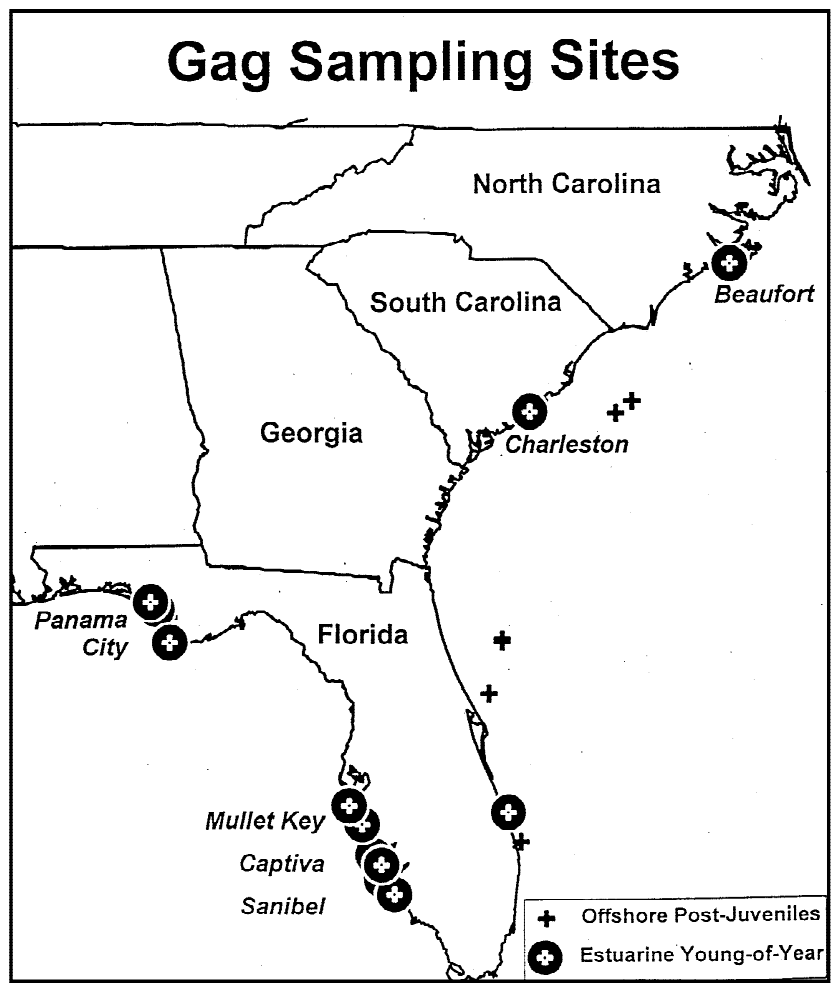

Figure 1. A map of the sampling locations for Mycteroperca microlepis taken during this study.

chance, suggest population subdivision or deviations from Mendelian ratios.

\section{Materials and Methods}

DNA samples were obtained from gag that were collected by research surveys and port sampling of commercial catches, from Beaufort, North Carolina, to Panama City, Florida (Figure 1). Tissue samples included heart tissue as well as blood and fin clips from tagged and released fish. The tissue was immediately placed in a $1.5-\mathrm{ml}$ centrifuge tube containing $1 \mathrm{ml}$ of a sodium dodecy sulfate (SDS)/urea lysis solution (1\% SDS/6 M urea). The samples were then transported to the laboratory and stored at room temperature. DNA was isolated using standard protocols (White and Densmore, 1992), and $5 \mu \mathrm{l}$ of each isolation was separated on a $0.8 \%$ agarose gel in TAE buffer to confirm the presence of an adequate amount of high molecular weight DNA. The final concentration of DNA in each sample was about 10 to $100 \mathrm{ng} / \mu \mathrm{l}$.

Eight sets of microsatellite primers (Table 1) were developed for gag, by cloning nuclear DNA segments that 
Table 1. Nucleotide Sequences of Microsatellite Primer Sets Designed to Amplify GT-Repeat Regions of the Gag Nuclear Genome*

\begin{tabular}{llr}
\hline $\begin{array}{l}\text { Primer } \\
\text { designation }\end{array}$ & Sequence & Result \\
\hline GAG007F & 5'-CTGTAATAGACAACCCACTGTAC & P \\
GAG007R & 5'-CCTGTAGCATCTTCACTAGCTG & \\
GAG010F & 5'-CTAGAGGATCATTTGACAATGTAG & P \\
GAG010R & 5'-CCTGACTAATCCACAGTAATTGC & \\
GAG013F & 5'-TTTGACACCACAGAAGAAGAAGG & M \\
GAG013R & 5'-TGTCCAATCACAGCACATCAG & \\
GAG023F & 5'-GCATTTGTGTTAGGATGACACT & P \\
GAG023R & 5'-CACATGGACAGGATTGAGGA & M \\
GAG031F & 5'-TGATAGAAACACGCATTCAC & P \\
GAG031R & 5'-ATGCTGCTTCAACAGTGT & \\
GAG038F & 5'-CCCCACCTCCCTTAACA & P \\
GAG038R & 5'-GCTGAATTGAGGAAATGAG & \\
GAG045F & 5'-GTGTGCATGTGAGAGAAAGT & P \\
GAG045R & 5'-GCCTTAACGGATGTCTTTCT & \\
GAG049F & 5'-ACTCTAATCTACAGCATATTCT & \\
GAG049R & 5'-CAGCTCGCCTGAAAGACT &
\end{tabular}

${ }^{\star} \mathrm{F}$ indicates forward primer; $\mathrm{R}$, reverse primer; $\mathrm{P}$, polymorphic locus; $\mathrm{M}$, monomorphic locus.

showed GT repeats, and by sequencing DNA segments flanking the region containing variable lengths of GT repeats (i.e., microsatellites). Microsatellites were identified according to the protocol of Tautz (1989), and polymerase chain reaction (PCR) primers were designed for clones containing at least eight repeats. These primers were used to amplify samples of gag DNA to identify those loci that contained sufficient polymorphism to meet the study objectives.

Amplification conditions were $2 \mu \mathrm{l}$ of template DNA, 5 $\mu \mathrm{l}$ of $10 \times$ buffer $\left(0.67 \mathrm{M}\right.$ Tris, $0.166\left(\mathrm{NH}_{4}\right)_{2} \mathrm{SO}_{4}$, and $10 \mathrm{mM}$ $\beta$-mercaptoethanol), $200 \mu \mathrm{M}$ dNTPs, $100 \mu \mathrm{M}$ of each primer, $32.5 \mu \mathrm{l}$ of water, and $2 \mathrm{mM} \mathrm{MgSO}_{4}$ ) for 35 cycles (one cycle $=30$ seconds at $94^{\circ} \mathrm{C}, 30$ seconds at $53^{\circ} \mathrm{C}, 2.5$ minutes at $72^{\circ} \mathrm{C}$ ). An initial screening for levels of variation was conducted on $4 \%$ metaphor (FMC, Inc.) gels. This screening indicated that dinucleotide repeats could easily be discerned on this gel system. To verify the consistency of scoring, samples containing all of the allelic variant identified by metaphor gels were amplified using a radiolabeled primer, and the products were separated on sequencing gels. These results confirmed patterns we had observed on metaphor gels, and the simpler metaphor gel was used to separate microsatellite alleles. Five of the eight microsatellite loci developed for this study proved to be polymorphic (Table 1); however, two of these (GAG007 and GAG023) were difficult to score owing to stuttering and were not included in the database.

All statistical analyses reported here were performed on the GENEPOP program of Raymond and Roussett (1995a). The tests for deviation from HW equilibrium were conducted for any deviation, rather than the alternative hypothesis of heterozygote deficiency (Raymond and Rousset, 1995b). In addition, we conducted global tests for HW equilibrium across all loci for each population and across all loci for the total sample following Raymond and Roussett (1995b). We refer the interested reader to the GENEPOP manual for the details of the methods used in computing the various statistics reported here. The significance levels assigned to multiple simultaneous tests among populations at individual loci were determined by the sequential Bonferroni procedure (see Rice, 1989). Although this procedure can be quite conservative, it does provide an indication of the level of significance of individual tests. The significance of allele frequency differences in pairwise comparisons of populations across all loci was estimated by a new approach, which computes the likelihood that $r$ of $n$ tests would exceed the 0.05 level by chance. This probability can be calculated from the likelihood function

$$
L=\sum_{i=r}^{n} \mathrm{C}(1-\alpha)^{n-r}(\alpha)^{r}
$$

where $n$ is the total number of tests, $r$ is the fraction of significant tests at a given $\alpha, \mathrm{C}$ is the factorial constant $(n ! /(r !(n-r) !)$, and we sum from $r$ to $n$. We have adopted this approach because we wish to examine the likelihood that $r$ of $n$ loci would exhibit significantly different gene frequencies between two populations by chance. This test can easily be extended to examine the probability that $r$ of $n$ tests for HW equilibrium at multiple loci and across multiple populations. It therefore serves as an independent check on the global tests for HW equilibrium derived by Raymond and Roussett (1995b). For convenience, we have calculated these probabilities for $\alpha=0.05$ and up to 10 tests (Table 2).

\section{Results}

The numerical solutions to the maximum likelihood equation (see above) suggest that when about a third or more of 
Table 2. The Results of the Likelihood Function for the Probabilities That a Specified Number of Tests Would Be Significantly Different from Expectations at $\alpha=0.05^{\star}$

\begin{tabular}{|c|c|c|c|c|c|c|c|c|c|}
\hline \multirow{2}{*}{$\begin{array}{l}\text { Number of } \\
\text { simultaneous } \\
\text { tests }\end{array}$} & \multicolumn{9}{|c|}{ Number of significant tests } \\
\hline & 2 & 3 & 4 & 5 & 6 & 7 & 8 & 9 & 10 \\
\hline 0 & 0.9025 & 0.857375 & 0.814506 & 0.773781 & 0.735092 & 0.698337 & 0.66342 & 0.630249 & 0.598737 \\
\hline 1 & 0.095 & 0.135375 & 0.171475 & 0.203627 & 0.232134 & 0.257282 & 0.279335 & 0.298539 & 0.315125 \\
\hline 2 & 0.0025 & 0.007125 & 0.013538 & 0.021434 & 0.030544 & 0.040623 & 0.051456 & 0.06285 & 0.074635 \\
\hline 3 & & 0.000125 & 0.000475 & 0.001128 & 0.002143 & 0.003563 & 0.005416 & 0.007718 & 0.010475 \\
\hline 4 & & & $6.25 \mathrm{E}-06$ & 2.97E-05 & $8.46 \mathrm{E}-05$ & 0.000188 & 0.000356 & 0.000609 & 0.000965 \\
\hline 5 & & & & $3.13 \mathrm{E}-07$ & $1.78 \mathrm{E}-06$ & $5.92 \mathrm{E}-06$ & $1.5 \mathrm{E}-05$ & $1.69 \mathrm{E}-06$ & $6.09 \mathrm{E}-05$ \\
\hline 6 & & & & & $1.56 \mathrm{E}-08$ & $1.04 \mathrm{E}-07$ & $5.36 \mathrm{E}-07$ & $5.92 \mathrm{E}-08$ & $1.07 \mathrm{E}-06$ \\
\hline 7 & & & & & & $7.81 \mathrm{E}-10$ & $5.94 \mathrm{E}-09$ & $2.54 \mathrm{E}-08$ & $2.41 \mathrm{E}-08$ \\
\hline 8 & & & & & & & $3.91 \mathrm{E}-11$ & $3.34 \mathrm{E}-10$ & $3.17 \mathrm{E}-10$ \\
\hline 9 & & & & & & & & $1.95 \mathrm{E}-12$ & $1.86 \mathrm{E}-11$ \\
\hline 10 & & & & & & & & & $9.77 \mathrm{E}-14$ \\
\hline
\end{tabular}

${ }^{*}$ To obtain the likelihood that $r$ (or more) of $n$ tests are significant by chance, simply sum the values in a column for all rows equal to and greater than $r$. See text for explanation of the likelihood function.

the loci involved in independent tests exceed $\alpha=0.05$, we should conclude that populations were genetically distinct (Table 2). Likewise for tests of HW equilibrium in a population, we should conclude that the sample was not drawn from a Mendelian population under the same conditions. The analysis does assume that loci are not genetically linked and are responding in a similar fashion to the pressures of mutation, migration, drift, and selection.

The gene frequency distributions for each population at each locus are presented in Table 3. We labeled the alleles according to their molecular weights, and the loci proved to be perfect dinucleotide repeats ranging from bases 132 to 146 (GAG010), 104 to 114 (GAG038), and 138 to 152 (GAG045). Overall the GAG010 and GAG045 loci are typical of microsatellites in that the most frequent alleles are in the center of the molecular weight range and the frequency distribution of alleles plotted against their molecular weights is, more or less, bimodal. GAG038 is unusual in that the most common allele is the smallest.

The $p$ values reported in Table 3 indicate the degree of conformity of genotypic distributions to HW proportions. These values are significantly different from expectations for all populations at the GAG010 and GAG045 loci, even when corrected for multiple simultaneous tests by the Bonferroni procedure. At the GAG038 locus, only Florida East Coast and West Coast populations differ from Mendelian expectations. The global test results for conformity to HW equilibrium across loci for each population using the Raymond and Rousset approach (Table 3) are all significant and strongly indicate that these samples are not drawn from Mendelian populations. This conclusion is supported by examination of Table 2; we see that the chance probability of two or more loci deviating from HW proportions is less than 0.01 . Thus we can safely conclude that none of the sampling locations appears to have Mendelian populations.

The $F_{i s}$ values reported in Table 3 indicate that there is an excess of homozygotes in all cases where significant deviations from HW equilibrium were noted. This could indicate the presence of "null" alleles, and we estimated the frequency of null alleles as $r=.2245$ using the calculation of Brookfield (1996, eq. 4). We would expect 12.4 null homozygotes in the total database if null alleles were this common, and we observed none. A portion of the individuals collected during this study (not included in the data) did fail to amplify, but the failures were at two or more of the loci and attributed to degraded DNA or sample contamination. For these reasons, we consider it unlikely that null alleles made a substantial contribution to $F_{i s}$, but cannot dismiss the possibility.

Other potential contributors to the large $F_{i s}$ values are the possibility the individuals that were heterozygous for alleles that differed by a single repeat were incorrectly scored as homozygotes for one of the alleles, and the po- 
Table 3. Gene Frequency Distributions at the Indicated Loci in Samples of Mycteroperca microlepis

\begin{tabular}{|c|c|c|c|c|c|c|c|}
\hline Locus & Alleles* & $\begin{array}{l}\text { North } \\
\text { Carolina }\end{array}$ & $\begin{array}{l}\text { South } \\
\text { Carolina }\end{array}$ & $\begin{array}{l}\text { Florida } \\
\text { East Coast }\end{array}$ & $\begin{array}{l}\text { Florida } \\
\text { West Coast }\end{array}$ & $\begin{array}{l}\text { Panama City, } \\
\text { Florida }\end{array}$ & Total \\
\hline \multirow[t]{11}{*}{ GAG010 } & 132 & 0.000 & 0.036 & 0.027 & 0.050 & 0.060 & 0.037 \\
\hline & 134 & 0.040 & 0.027 & 0.113 & 0.025 & 0.050 & 0.059 \\
\hline & 136 & 0.160 & 0.179 & 0.253 & 0.013 & 0.220 & 0.181 \\
\hline & 138 & 0.220 & 0.134 & 0.260 & 0.175 & 0.420 & 0.246 \\
\hline & 140 & 0.320 & 0.339 & 0.167 & 0.188 & 0.130 & 0.217 \\
\hline & 142 & 0.240 & 0.259 & 0.033 & 0.313 & 0.090 & 0.163 \\
\hline & 144 & 0.020 & 0.027 & 0.113 & 0.075 & 0.010 & 0.057 \\
\hline & 146 & 0.000 & 0.000 & 0.033 & 0.163 & 0.020 & 0.041 \\
\hline & $N$ & 25 & 56 & 75 & 40 & 50 & 246 \\
\hline & $p$ & 0.0131 & 0.0001 & 0.0001 & 0.0041 & $<0.0001$ & 0.0005 \\
\hline & $F_{i s}$ & 0.441 & 0.401 & 0.300 & 0.325 & 0.363 & \\
\hline \multirow[t]{9}{*}{ GAG038 } & 104 & 0.840 & 0.875 & 0.827 & 0.850 & 0.790 & 0.835 \\
\hline & 106 & 0.100 & 0.107 & 0.100 & 0.113 & 0.130 & 0.110 \\
\hline & 108 & 0.060 & 0.018 & 0.040 & 0.025 & 0.070 & 0.041 \\
\hline & 110 & 0.000 & 0.000 & 0.013 & 0.013 & 0.000 & 0.006 \\
\hline & 112 & 0.000 & 0.000 & 0.013 & 0.000 & 0.010 & 0.006 \\
\hline & 114 & 0.000 & 0.000 & 0.007 & 0.000 & 0.000 & 0.002 \\
\hline & $N$ & 25 & 56 & 75 & 40 & 50 & 246 \\
\hline & $p$ & 1.000 & 1.000 & 0.0002 & 0.0326 & 0.5635 & 1.000 \\
\hline & $F_{i s}$ & -0.120 & -0.114 & 0.044 & 0.066 & 0.050 & \\
\hline \multirow[t]{11}{*}{ GAG045 } & 138 & 0.020 & 0.045 & 0.033 & 0.075 & 0.050 & 0.045 \\
\hline & 140 & 0.100 & 0.214 & 0.180 & 0.213 & 0.320 & 0.213 \\
\hline & 142 & 0.100 & 0.250 & 0.353 & 0.150 & 0.310 & 0.262 \\
\hline & 144 & 0.180 & 0.223 & 0.300 & 0.213 & 0.160 & 0.228 \\
\hline & 146 & 0.120 & 0.125 & 0.127 & 0.125 & 0.090 & 0.118 \\
\hline & 148 & 0.200 & 0.107 & 0.007 & 0.175 & 0.050 & 0.085 \\
\hline & 150 & 0.220 & 0.036 & 0.000 & 0.050 & 0.020 & 0.043 \\
\hline & 152 & 0.060 & $<0.0001$ & $<0.0001$ & $<0.0001$ & $<0.0001$ & 0.006 \\
\hline & $N$ & 25 & 56 & 75 & 40 & 50 & 246 \\
\hline & $p$ & 0.0131 & 0.0001 & 0.0001 & 0.0040 & 0.0001 & 0.0131 \\
\hline & $F_{i s}$ & 0.021 & 0.238 & 0.118 & 0.142 & 0.301 & \\
\hline
\end{tabular}

${ }^{\star} N$ indicates the sample size; $p$, the probability of departure from Hardy-Weinberg expectations; $F_{i s}$, the inbreeding coefficient for each population.

tential that smaller alleles are favored in PCR and could result in incorrect scoring of heterozygotes containing the larger alleles as homozygotes for the smaller allele. In the former case, we would expect that heterozygotes whose alleles differed by a single step would be the largest contributor to the overall heterozygote deficiency. In Figure 2, we have plotted the deviation from HW at the GAG010 locus as $D$ according to Selander (1970) for heterozygotes that differ by $1,2,3$, and 4 or more repeats. It is clear from this illustration that heterozygotes that differ by 3 or more repeats are the largest contributors to the overall heterozygote deficiency. In addition, heterozygotes that differed by a single step were actually overrepresented compared with the expectation for this locus. Results were similar for the GAG045 locus, except that single-step heterozygotes were underrepresented. Nonetheless, heterozygotes that differed by two or more repeats were the largest contributors to the overall heterozygote deficiency.

Examination of the potential for PCR bias as a contributor to heterozygote deficiency is not as straightforward as the test for misscoring of adjacent size classes. We cannot compute the heterozygote deficiency associated with the 


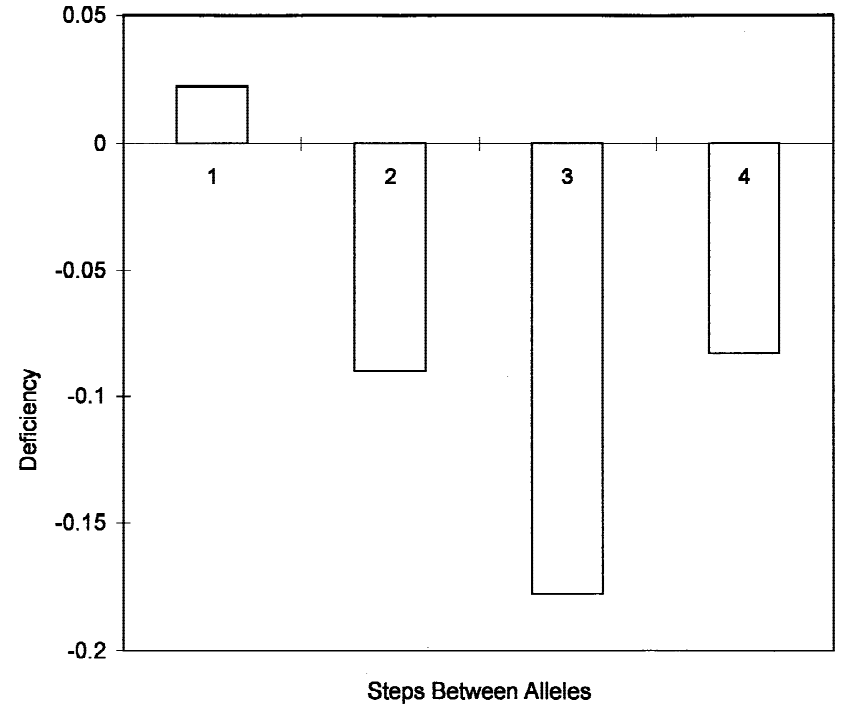

Figure 2. The deviation from HW equilibrium for heterozygotes at the GAG010 locus, where the alleles differ by 1, 2, 3, and 4 or more GT repeats. The deviations are reported as $D$ according to Selander (1970).

smaller alleles and compare it with the deficiency associated with larger alleles because these estimates are not independent. We can examine the problem by computing the homozygote excesses associated with each allele (which are by definition $F_{i s}$ estimates and independent) and converting these to heterozygote deficiencies. We have plotted these estimates for each allele for the GAG010 locus (Figure 3). Figure 3 shows that the overall heterozygote deficiency does not appear to be associated with allele size class. The correlation coefficient was 0.54 and not significant. Thus we can discount misscoring of single-step heterozygotes and amplification bias as major contributors to the heterozygote deficiency.

Pairwise tests for gene frequency differences among populations at the GAG010 locus show that all populations were significantly different except North Carolina and South Carolina populations (Table 4). None of the populations differed at the GAG038 locus, while all comparisons were significant at the GAG045 locus, except those involving South Carolina and Gulf of Mexico populations (Table 4). For the pairwise comparisons of populations, we require $p<.05$ for at least two of the three loci. From Table 4, we see that all comparisons meet this criteria, except those involving South Carolina, which differs only from the East Coast of Florida at two or more loci.

The partitioning of genetic variance within and between populations (Table 5) reinforces conclusions that

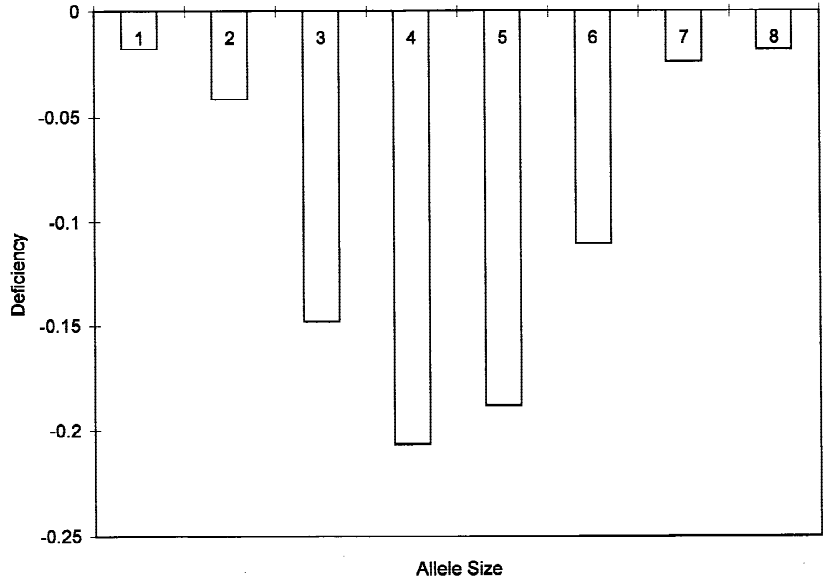

Figure 3. The deviation from $\mathrm{HW}$ equilibrium attributable to each allele at the GAG010 locus (see text for details). The deviations are reported as $D$ according to Selander (1970).

might be drawn from HW tests and pairwise comparisons of gene frequencies. Here it is shown that variation within populations is, by far, larger than the component attributable to differences between populations. This should not be taken to imply that the differences among samples lack significance (see Table 4). Wright (1943) designed the $F$ statistics to partition the total genetic variance $\left(F_{i t}\right)$ into within population $\left(F_{i s}\right)$ and between population $\left(F_{s t}\right)$ components analogous to analysis of variance. The fact that $F_{i s}$ is larger than $F_{s t}$ does not mean that the allele frequency differences among samples are not statistically significant. Clearly, they are.

An assessment of the genotypic linkages among loci for each population and in the total data (Table 6) shows that none of the loci are linked in any of the populations. The only value that is even close to significance (West Coast Florida, GAG038 vs GAG045) is not significant when adjusted for multiple tests. These comparisons are important because they validate the independence assumptions in the global HW equilibrium tests conducted by GENEPOP (Raymond and Roussett, 1995a) and the likelihood approach derived from the maximum likelihood equation (above).

\section{Discussion}

We have shown here that there are pronounced allele frequency differences (Table 4) among M. microlepis samples taken from the Atlantic and Gulf of Mexico. In addition, 
Table 4. Comparison of Gene Frequencies at the Indicated Loci Among Populations*

\begin{tabular}{|c|c|c|c|c|}
\hline & South Carolina & $\begin{array}{l}\text { Florida } \\
\text { East Coast }\end{array}$ & $\begin{array}{l}\text { Florida } \\
\text { West Coast }\end{array}$ & $\begin{array}{r}\text { Panama City, } \\
\text { Florida }\end{array}$ \\
\hline \multicolumn{5}{|l|}{ GAG010 } \\
\hline North Carolina & .7780 & $<.0001$ & $<.0001$ & .0030 \\
\hline South Carolina & & $<.0001$ & $<.0001$ & .0001 \\
\hline Florida East Coast & & & $<.0001$ & .0020 \\
\hline Florida West Coast & & & & $<.0001$ \\
\hline \multicolumn{5}{|l|}{ GAG038 } \\
\hline North Carolina & .3733 & .9589 & .7604 & .9248 \\
\hline South Carolina & & .5623 & .7562 & .1255 \\
\hline Florida East Coast & & & .9469 & .6934 \\
\hline Florida West Coast & & & & .3757 \\
\hline \multicolumn{5}{|l|}{ GAG045 } \\
\hline North Carolina & .0013 & $<.0001$ & .0190 & $<.0001$ \\
\hline South Carolina & & .0011 & .5710 & .3072 \\
\hline Florida East Coast & & & $<.0001$ & .0051 \\
\hline Florida West Coast & & & & .0103 \\
\hline
\end{tabular}

${ }^{\star}$ The values indicate the probability that the populations are statistically identical at the indicated loci.

these samples do not conform to HW expectations, suggesting that they are not Mendelian populations (Table 3). These observations are open to at least two interpretations. First, taken at face value they would indicate substantial population structure throughout the range of this species. This interpretation would demand some biological or physical restrictions of gene flow. Second, and most disturbing, is that the data may reflect the genetic consequences of current population declines and changing sex ratios (McGovern et al., 1998; Coleman et al., 1996). We should stress that the available information may not provide a strong conclusion regarding the relative merits of either of these interpretations and there is no a priori reason why they should be mutually exclusive.

We find it difficult to believe that the present data actually reflect strong population subdivision in M. microlepis. Restricted gene flow could easily promote the gene frequency differences noted among samples. It is difficult to understand how gene flow could be restricted in this species or how such restrictions could underlie the significant departures from HW equilibrium noted in each collection. The distribution of M. microlepis along the Gulf and Atlantic Coasts is not substantially interrupted by long stretches of unsuitable habitat, and there are no obvious physical barriers. Adults are known to migrate over hundreds of kilometers (Van Sant et al., 1994), and juvenile M. micro-
Table 5. F Statistics for the Microsatellite Loci Examined in $M y c$ teroperca microlepis

\begin{tabular}{lllr}
\hline Locus & $F_{i s}$ & $F_{s t}$ & $F_{i t}$ \\
\hline GAG010 & .3530 & .0136 & .3618 \\
GAG038 & .0045 & -.0011 & .0035 \\
GAG045 & .1760 & .0066 & .1815 \\
All loci & .2242 & .0084 & .2307
\end{tabular}

lepis are known to appear off Long Island, New York, hundreds of kilometers from the nearest known spawning aggregation (K. Able, personal communication). This suggests that restricted movements of adults and early life stages do not appear to be plausible explanations for the observed differences among sampling locations.

Significant departures from HW accompanied by heterozygote deficiencies (positive $F_{i s}$ values) can result from a number of factors including inbreeding owing to limited population size, selection, assortative mating, the presence of null alleles, and the Wahlund effect (Wahlund, 1928). One or more of these features has been invoked to account for these observations in marine species (Koehn et al., 1984; Benzie and Stoddard, 1992; Karl and Avise, 1992; Hare and Avise, 1996). We have suggested above that null alleles are 
Table 6. Tests for Linkage Disequilibrium Among Loci for Each Sampling Location and in the Combined Data for Mycteroperca microlepis

\begin{tabular}{llll}
\hline Location & Locus 1 & Locus 2 & $P$ value \\
\hline North Carolina & GAG010 & GAG038 & .6855 \\
North Carolina & GAG010 & GAG045 & .2551 \\
North Carolina & GAG038 & GAG045 & .4187 \\
South Carolina & GAG010 & GAG038 & .2127 \\
South Carolina & GAG010 & GAG045 & .7631 \\
South Carolina & GAG038 & GAG045 & .7335 \\
East Coast Florida & GAG010 & GAG038 & .2017 \\
East Coast Florida & GAG010 & GAG045 & .0995 \\
East Coast Florida & GAG038 & GAG045 & .4343 \\
West Coast Florida & GAG010 & GAG038 & .4545 \\
West Coast Florida & GAG010 & GAG045 & .2641 \\
West Coast Florida & GAG038 & GAG045 & .0362 \\
Panama City, Florida & GAG010 & GAG038 & .1714 \\
Panama City, Florida & GAG010 & GAG045 & .4659 \\
Panama City, Florida & GAG038 & GAG045 & .2407 \\
Total data & GAG010 & GAG038 & .27478 \\
Total data & GAG010 & GAG045 & .27998 \\
Total data & GAG038 & GAG045 & .19633 \\
\hline & & & \\
\hline
\end{tabular}

not likely to account for heterozygote deficiencies noted in these data and selection and assortative mating are not likely to be the factors influencing the distribution of alleles at microsatellite loci (Lander, 1989). If the Wahlund effect were a likely candidate, it would have to be operating on a microgeographic scale.

In some studies (Avise and Shapiro, 1986), data such as those presented here have been actively pursued. One hope was that such information would indicate inbreeding effects that would promote kinship among juveniles and support a variety of sociobiological inferences regarding the behavior of serranid species (J.C. Avise, personal communication). While the data did not support close kinship among individuals, a number of problems associated with the sampling could have precluded a positive result (Avise and Shapiro, 1986). Ruzzante et al. (1996) presented data on Gadus morhua that are remarkably similar to ours. Larval cod were shown to have significant heterozygote deficiencies and gene frequency differences among cohorts, but these deviations from HW expectations disappeared within cohorts judged to be the same age.

The observations described above were taken to indicate kinship with age groups and support the genetic "sweepstakes hypothesis." This hypothesis proposes that most of the offspring produced in a given cohort are the progeny of a very restricted portion of the spawning population. This process can lead to diminished genetic variation, gene frequency differences among cohorts, and kinship among individuals within cohorts. The basic tenets of this hypothesis can be extracted from a number of lines of reasoning and are supported by a variety of empirical data (see Hedgecock, 1994; Ruzzante et al., 1996; Li and Hedgecock, 1998). In this light, the present data are perfectly understandable because the number of adults that contribute to a given year class could be limited by (1) decline in overall abundance (McGovern et al., 1998), (2) extremely skewed sex ratios compared with historical values (Coleman et al., 1996; McGovern et al., 1998), (3) variance in reproductive success owing to high fecundity of individual females (Collins et al., 1987; Hedgecock, 1994), and (4) the segregation of spawning grounds and nursery areas (Collins et al., 1987; Keener et al., 1988; Coleman et al., 1996; McGovern et al., 1998). Collectively these phenomena should lead to inbreeding and significant differences among samples and homozygote excesses.

The genetic ramifications of population declines have been understood for some time (see Nei et al., 1975; Nelson and Soule, 1987) and do not need to be discussed further. The significance of increasing skew in sex ratios (Coleman et al., 1996; McGovern et al., 1998) may not be so obvious. It has been suggested that fishing pressures preferentially remove the larger, more aggressive individuals from grouper spawning aggregations (Gilmore and Jones, 1992), and these individuals are, for the most part, males. This could substantially reduce $N_{e}$ according to the well-known formula of Wright (1931), and further the loss of genetic variability associated with population declines. We have no evidence that genetic variation has declined in M. microlepis, as this is the first study of genetics in this species, and the process is likely to be delayed owing to the length of the generation time (Nei et al., 1975). A restriction on the number of males in spawning populations would have more immediate effects on the genetic relationships among progeny. We would expect that offspring would be more likely to be genetically related and exhibit large, positive $F_{i s}$ values such as those noted in this study.

From the conservation point of view, the suggestion that gag populations may be exhibiting the initial genetic consequences of population declines and changes in sex ratios is ominous. Nei et al. (1975) have shown that such population bottlenecks inevitably lead to loss of genetic di- 
versity, even though the process may be delayed by the organism's generation time. The loss of genetic diversity at microsatellite loci is not likely to affect the long-term survival of a species, as the adaptive significance of such loci is questionable (see Lander, 1989). However, if such losses are driven by population bottlenecks, they will almost certainly result in the loss of variation at loci that are of adaptive significance unless the process is countered by strong balancing selection (see Wright, 1931). In the final analysis, we view the data presented here as an exclamation point to the studies on declining population numbers (McGovern et al., 1998) and changing sex ratios (Coleman et al., 1996) in this species. Collectively, they underscore the need to increase conservation measures for this resource.

\section{ACKNOWLEDGMENTS}

We appreciate the efforts of T. Brandt and J. McGovern in collecting many of the samples used in this study. The comments of two anonymous reviewers improved an earlier version of the manuscript. The research was partially supported by MARFIN grants NA37FF0052 and NA57FF0058, S-K grant NA57FD0030, NMFS-MARMAP grant 50WCNF606013, and by The South Carolina Sea Grant Consortium, grant R/F-1C. This is contribution 98-6 to the Cooperative Institute of Fisheries Molecular Biology and contribution 415 to the South Carolina Department of Natural Resources, Marine Resources Division.

\section{REFERENCES}

Avise, J.C. and Shapiro, D.Y. (1986). Evaluating kinship of newly settled juveniles with social groups of the coral reef fish Anthias squamipinnis. Evolution 40:1051-1059.

Benzie, J.A.H, and Stoddard, J.A. (1992). Genetic structure of crown-of-thorns starfish (Acanthaster planci) in Australia. Mar Biol 112:631-639.

Brookfield, J.F.Y. (1996). A simple new method for estimating null allele frequency from heterozygote deficiency. Mol Ecol 5:453-455.

Carter, J.J. (1989). Grouper sex in Belize. Nat Hist 61-68.

Coleman, F.C., Koeing, C.C., and Collins, L.A. (1996). Reproductive styles of shallow-water groupers (Pisces:Serranidae) in the eastern Gulf of Mexico and the consequences of fishing spawning aggregations. Environ Biol Fish 47:129-141.
Colin, P.L., Shapiro, D.Y., and Weiler, D. (1987). Aspects of the reproduction of two groupers, Epinephelus guttatus and E. striatus in the West Indies. Bull Mar Sci 40:220-230.

Collins, M.R., Waltz, C.W., Roumillat, W.A., and Stubbs, D.L. (1987). Contribution to the life history and reproductive biology of gag, Mycteroperca microlepis (Serranidae), in the South Atlantic Bight. Fish Bull 85(3):648-653.

Craig, A.E. (1969). The grouper fishery of Cay Glory, British Honduras. Ann Assoc Am Geog 59(2):252-263.

Gilmore, R.G., and Jones, R.J. (1992). Color variation and associated behavior in the epinepheline groupers, Mycteroperca microlepis (Goode \& Bean) and M. phenax Jordan \& Swain. Bull Mar Sci 51:84-103.

Hare, M.P., and Avise, J.C. (1996). Molecular genetic analysis of a stepped multilocus cline in the American oyster (Crassostrea virginica). Evolution 50:2305-2315.

Hedgecock, D. (1994). Does variance in reproductive success limit effective population sizes of marine organisms? In Genetic and Evolution of Marine Organisms, Beaumont, A.R. (ed.). London: Chapman and Hall, 122-134.

Karl, S.A., and Avise, J.C. (1992). Balancing selection at allozyme loci in oysters; implications from nuclear RFLPs: Science 256:100102.

Keener, P. Johnson, G.D., Stender, B.W., Brothers, W.B., and Beatty, H.R. (1988). Ingress of postlarval gag, Mycteroperca microlepis (Pisces: Serranidae), through a South Carolina barrier island inlet. Bull Mar Sci 42(3):376-396.

Koehn, R.K., Hall, J.G., Innes, D.J., and Zera, A.J. (1984). Genetic differentiation of Mytilus edulis in eastern North America. Mar Biol 79:117-126.

Koenig, C.C., Coleman, F.C., Collins, L.A., Sadovy, Y., and Colin, P.L. (1996). Reproduction in gag (Mycteroperca microlepis) (Pisces: Serranidae) in the eastern Gulf of Mexico and the consequences of fishing spawning aggregations, p. 60-74. In: Biology, Fisheries and Culture of Tropical Groupers and Snappers, ICLARM Conf. Proc. vol. 48. Arreguín-Sánchez, F., Munro, J.L., Balgos, M.C., Pauly, D. (eds.). 60-74.

Lander, E.S. (1989). DNA fingerprinting on trial. Nature 339:501505.

Li, G., and Hedgecock, D. (1998). Genetic heterogeinity, detected by PCR-SSCP, among samples of larval Pacific oysters (Crassostrea gigas) supports the hypothesis of large variance in reproductive success. Can J Fish Aquat Sci 55:1025-1033.

McGovern, J.C., Wyanski, D.M., Pashuk, O., Manooch, C.S. III, and Sedberry, G.R. (1998). Changes in the sex ratio and size at maturity of gag, Mycteroperca microlepis, from the Atlantic coast of 
the southeastern United States during 1976-1995. Fish Bull 96: 797-807.

Nei, N., Maruyama, T., and Chakraborty, R. (1975). The bottleneck effect and genetic variability in populations. Evolution 29:110.

Nelson, K., and Soule, M. (1987). Genetical conservation of exploited fishes. In: Population Genetics and Fishery Management, Ryman, N., and Utter, F. (eds.). Seattle: University of Washington Press, 345-368.

Raymond, M., and Rousset, F. (1995a). GENEPOP (version 1.2): population genetics software for exact tests and ecumenicism. $J$ Hered 86:248-249.

Raymond, M., and Rousset, F. (1995b). Testing heterozygote excess and deficiency. Genetics 140:1415-1419.

Rice, W.R. (1989). Analyzing tables of statistical tests. Evolution 43:223-225.

Richards, W.J., and Lindeman, K.C. (1987). Recruitment dynamics of reef fishes: planktonic processes, settlement and demersal ecologies, and fishery analysis. Bull Mar Sci 41(2):392-410.

Ruzzante, D.E., Taggart, C.T., and Cook, D. (1996). Spatial and temporal variation in the genetic composition of larval cod (Gadus morhua) aggregation: cohort contribution and genetic stability. Can J Fish Aquat Sci 53:2695-2705.

Sadovy, Y., Colin, P.L., and Domeier, M.L. (1994). Aggregation and spawning in the tiger grouper, Mycteroperca tigris (Pisces:Serranidae). Coepia 1994:511-616.
Selander, R.K. (1970). Behavior and genetic variation in natural populations. Am Zool 10:53-65.

Shapiro, K.Y. (1987). Reproduction in groupers. In: Tropical Snappers and Groupers: Biology and Fisheries Management, Popovina, J.J., and Ralston, S. (eds.). Westview Press, 295-317.

Tautz, D. (1989). Hypervariability of simple sequences as a general source for polymorphic DNA markers. Nucleic Acids Res 17(16): 6463-6471.

Van Sant, S.B., Collins, M.R., and Sedberry, G.R. (1994). Preliminary evidence from a tagging study for a gag (Mycteroperca microlepis) spawning migration with notes on the use of oxytetracycline for chemical tagging. Proc Gulf Carib Fish Inst 43:417-428.

Waschkewitz, R., and Wirtz, P. (1990). Annual migration and return to the same site by an individual grouper, Epinephelus alexandrinus (Pisces:Serranidae). J Fish Biol 36:781-782.

Weir, B.S., and Cockerham, C.C. (1984). Estimating F-statistics for the analysis of population structure. Evolution 38:1358-1370.

White, P.S., and Densmore, L.D. III. (1992). Mitochondrial DNA isolation. In: Molecular Genetic Analysis of Populations: A Practical Approach, Hoelzel, A.R. (ed.). New York, N.Y.: Oxford University Press, 29-58.

Wright, S. (1931). Evolution in Mendelian populations. Genetics 16:97-159.

Wright, S. (1943). Isolation by distance. Genetics 28:114-138. 